\title{
REFLEXÕES SOBRE A COORDENAÇÃO DO SISTEMA AGROINDUSTRIAL DA MANDIOCA: DESAFIOS PARA A PESQUISA
}

\author{
Reflections on the Coordination of the Agricultural System of the Cassava: Challenges for Research
}

\begin{abstract}
RESUMO
A competitividade da cadeia da mandioca está comprometida, principalmente, devido a falhas de governança. Tais dificuldades foram apresentadas e analisadas em numerosas pesquisas, contudo, a produção acadêmica se ateve basicamente em descrever a estrutura de governança, as transações e o ambiente institucional e defender formas contratuais que não têm apresentado aderência prática pelos agentes. Em vista disso, o objetivo é compreender, a partir dos resultados já apresentados em literatura científica prévia, quais caminhos a pesquisa pode tomar para avançar na disseminação de conhecimento sobre formatos eficientes de governança no sistema agroindustrial da mandioca. Por meio de pesquisa bibliográfica em uma amostra de 58 pesquisas, seguida de análise de conteúdo, destacam-se requisitos específicos de estudo, como a análise dos elementos que interferem na racionalidade limitada dos agentes, as formas que o oportunismo assume, o efetivo peso da frequência das transações e a amplitude e convergência do ambiente institucional. As análises das estruturas de governança são divergentes quanto à compreensão das vantagens dos modos diferenciados de organização das firmas, o que demanda estudos mais aprofundados e com maior rigor científico para equacionar tais discrepâncias. Como contribuição, o estudo possibilita a reflexão sobre a percepção acadêmica da coordenação do sistema agroindustrial da mandioca, defende a atividade de pesquisa como elemento propulsor de ações que geram competitividade e incentiva a continuidade e a sofisticação de estudos sobre a cadeia da mandioca.
\end{abstract}

Evelini Lauri Morri Garcia

Universidade Estadual de Maringá

evelinilaurimorri@hotmail.com

Sandra Mara Schiavi Bankuti

Universidade Estadual de Maringá

sandraschiavi@gmail.com

Recebido em: 20/11/2018. Aprovado em: 18/02/2020.

Avaliado pelo sistema double blind review

Avaliador científico: Elisa Reis Guimarães

\begin{abstract}
The competitiveness of the cassava chain is mainly due to poor governance. Such difficulties have been presented and analyzed in numerous researches; however, academic production has basically focused on describing the governance structure, transactions and the institutional environment and defending contractual forms that have not shown practical adherence by agents. In view of this, the objective is to understand, based on the results already presented in previous scientific literature, the ways in which research can take to advance the dissemination of knowledge about efficient governance formats in the cassava agroindustrial system. Through bibliographic research in a sample of 58 researches, followed by content analysis, we highlight specific study requirements, such as the analysis of the elements that interfere in the limited rationality of the agents, the forms that opportunism assumes the effective weight of frequency of transactions and the breadth and convergence of the institutional environment. Analyzes of governance structures diverge as to the understanding of the advantages of differentiated modes of organization of firms, which requires more in-depth studies with more scientific rigor to equate such discrepancies. As a contribution, the study enables reflection on the academic perception of the coordination of the cassava agroindustrial system, defends the research activity as an element that propels actions that generate competitiveness and encourages the continuity and sophistication of studies on the cassava chain.
\end{abstract}

Palavras-chave: Competitividade. Custos de Transação. Ambiente Institucional. Estrutura de Governança.

Keywords: Competitiveness. Transaction Costs. Institutional Environment. Governance Structure.

\section{INTRODUÇÃO}

O Brasil é o quarto maior produtor de mandioca do mundo (DEPARTAMENTO DE ECONOMIA RURAL, 2015). O cultivo está presente em todos os estados do país e atende desde a demanda alimentar direta, por meio da agricultura de subsistência, até sistemas agroindustriais, sendo este o segmento mais desenvolvido (PIGATTO et al., 2015).No uso industrial, a mandioca pode ser transformada em farinha e polvilho azedo, utilizados essencialmente na base alimentar, ou em fécula, que é a commodity de amido mais exportada no mundo e matéria-prima de diversas indústrias (VILPOUX, 2011).

Apesar do alto volume de produção de mandioca e da existência de uma crescente demanda internacional de fécula, a representatividade de derivados da mandioca mostra-se irrisória na balança de exportações do Brasil. Além disso, a área plantada diminuiu $10 \%$ ao longo dos últimos 
anos, sinalizando que a cadeia da mandioca está perdendo espaço para outras atividades rurais (DEPARTAMENTO DE ECONOMIA RURAL, 2015).A ausência de arranjos institucionais eficientes entre produtores e agentes industriais é apontada como principal entrave da competitividade da cadeia da mandioca(ALVES, 2012; ALVES et al., 2007b; CARDOSO, ALVES, FELIPE, 2007; CARDOSO, BARROS, 2004; FELIPE et al., 2010; SOUZA et al. 2005; VILPOUX, 2011).

As dificuldades relacionadas à cadeia da mandioca no Brasil foram apresentadas e analisadas em numerosas pesquisas acadêmicas considerando que a conduta e o desempenho das organizações podem ser compreendidos por meio das relações em que estão incorporados (GULATI; NOHRIA; ZAHEER, 2000). Contudo, a produção acadêmica se ateve basicamente em descrever a estrutura de governança, as transações e o ambiente institucional. Os resultados destas pesquisas apontam amplas fragilidades na coordenação da cadeia e contribuições limitadas, visto que, em geral, defendem formas contratuais que não têm apresentado aderência prática pelos agentes. Considerando que as organizações atuam em um ambiente complexo e não podem ser avaliadas sem uma referência a suas relações com muitas outras organizações (JARILLO, 1988), as reflexões acadêmicas acerca das dificuldades presentes na cadeia da mandioca precisam avançar por meio de análises minuciosas e sustentadas por parâmetros teóricos robustos, a fim de oferecer contribuições ao desenvolvimento, tanto teórico quanto empírico, desta cadeia.

Nesta pesquisa, são compiladas análises realizadas em pesquisas sobre a cadeia brasileira da mandioca e apresenta-se como a estrutura de governança, as transações e o ambiente institucional desta cadeia agroindustrial são caracterizados nos estudos. O objetivo é compreender, a partir dos resultados já apresentados em literatura científica prévia, quais caminhos a pesquisa pode tomar para avançar na disseminação de conhecimento sobre formatos eficientes de governança no sistema agroindustrial da mandioca. A principal motivação para o estudo deve-se ao reconhecimento de que falhas de coordenação no agronegócio afetam significativamente a competitividade do setor (FARINA, 1999; MAERTENS, SWINNEN, 2015).

Os constructos aplicáveis à análise proposta nesta pesquisa estão amparados em elementos teóricos da Economia dos Custos de Transação (ECT) representados por pressupostos comportamentais e características das transações (WILLIAMSON, 1973). A ECT defende a influência da dinâmica institucional e das variáveis transacionais nas organizações das firmas e dos mercados, alegando que estes incorporam os efeitos e as interações com o ambiente institucional (FARINA, 1999; MACHER, RICHMAN, 2008). Desta forma, a economia organizacional deve se atentar às atividades realizadas entre as firmas, suas características e as relações contratuais mútuas, visto que estas se vinculam à estrutura de governança (COASE, 1937) e colaboram com a compreensão da natureza das formas de regulação das atividades econômicas (GRANDORI; SODA, 1995).

A pesquisa mostra-se importante visto que não se pode mais ignorar os problemas organizacionais na análise da competitividade no agronegócio, ainda que isso apresente desafios para sua operacionalização (FARINA, 1999).As pesquisas sobre a mandioca têm apresentado enfoque demasiado na análise das características das cadeias em localidades específicas. Estudos de caso permitem a primeira aproximação com a realidade, porém, não são suficientes para compreender um sistema produtivo em sua totalidade (ZYLBERSZTAJN, 2005). Os pesquisadores também são agentes de disseminação de boas práticas na agricultura, sendo as pesquisas recursos que contribuem com o fortalecimento da competitividade do agronegócio (LOPES; OLIVEIRA, 2009). Esta realidade mostra-se convidativa a um maior aprofundamento no reconhecimento dos elementos que interferem no sistema da mandioca, visto a sua potencialidade de geração de renda, criação de empregos e condições de atenuar o êxodo populacional das áreas rurais (PIGATTO et al., 2015; VILPOUX, 2011).

Enquanto contribuições, o estudo permite compilar as falhas de coordenação, institucional e de mercado presentes na cadeia da mandioca e identificadas em pesquisas, utilizando a ECT como embasamento teórico. A partir desta análise tem-se a oportunidade de observar pontos de convergência e divergência dos estudos acerca dos problemas que permeiam esta cadeia. Isso permite elencar áreas de pesquisa que podem avançar teórica e empiricamente na disseminação deformas de governança, sugerindo análises ainda não realizadas de microelementos e suas formas, origens e reflexos. Esta lente implica em benefícios que a agricultura pode obter da abordagem econômica dos custos de transação, assim como ajuda a ampliar e avançar a própria teoria (MACHER; RICHMAN, 2008).

\section{ECONOMIA DOS CUSTOS DE TRANSAÇÃO E O PAPEL DA COORDENAÇÃO EMSISTEMAS PRODUTIVOS}

A Economia dos Custos de Transação (ECT) é uma teoria econômica que foi construída como uma crítica à teoria clássica da firma. Suscita a compreensão 
das organizações como estruturas de governança e que estas podem ser desenvolvidas de diversas formas, sendo que cada formato corresponde a um nível específico de coordenação e de eficiência (WILLIAMSON, 1973). Em vista disso, a transação, objeto de análise desta teoria, ocorre por meio de contratos que podem ter distintas configurações as quais implicam em diferentes níveis de custos (WILLIAMSON, 2000). Com isso, o pressuposto neoclássico do custo de transação igual a zero é tratado pela ECT como um evento irreal (COASE, 1937).

A partir deste conceito, a ECT destaca que custos de transação podem ser minimizados e gerar eficiência às organizações por meio de arranjos eficientes que podem ser analisados sob a perspectiva dos contratos (JARILLO, 1988; MACHER, RICHMAN, 2008). Esta percepção é acompanhada da ênfase nas instituições, visto que são passíveis de análise, que afetam e são afetadas pelas firmas (ZYLBERSZTAJN, 2005). Ou seja, que a conduta e desempenho das empresas são influenciados pelas relações em que estão inseridos (GULATI; NOHRIA; ZAHEER, 2000). Para isso, a ECT ampara-se nos preceitos comportamentais da racionalidade limitada e do oportunismo (WILLIAMSON, 1973).

A racionalidade limitada implica na incompletude dos contratos devido à impossibilidade de detalhar todos os elementos das transações. Ou seja, representa um problema ex-ante ao contrato (WILLIAMSON, 1973). Em um contrato incompleto, os custos de transação podem ser majorados quando eventos inesperados ocorrem e culminam na necessidade de adaptação das partes. Estes episódios, normalmente, geram custos adicionais aos previstos no momento do contrato, e, dependendo do seu volume, podem inviabilizar a continuidade das atividades (MACHER; RICHMAN, 2008). Por isso, a adaptação é considerada o problema central da organização econômica (WILLIAMSON, 2000).

O outro elemento estrutural da ECT, o oportunismo, é considerado como a possibilidade do contrato ser rescindido. Isso pode ocorrer devido a situações que levam uma das partes a romper o acordo devido à obtenção de vantagens com a descontinuidade das atividades. Com isso, a outra parte do contrato é possivelmente prejudicada e seus custos de transação são majorados (FARINA, 1999). O oportunismo representa um problema ex-post ao contrato (WILLIAMSON, 1973) e, para diluí-lo, é necessário que haja confiança nas relações entre os agentes, que é a capacidade empreendedora fundamental para reduzir os custos e tornar a existência dos vínculos economicamente viável (JARILLO, 1988).
Considerando que os custos de transação ocorrem a partir de eventos suscetíveis à racionalidade limitada e/ ou ao oportunismo, os agentes buscam formas de relações organizacionais que minimizam os efeitos destes aspectos (MACHER; RICHMAN, 2008). Visto que a racionalização dos custos de transação por meio da eficiência das relações é o objetivo dos contratos, é preciso analisar com minúcia os elementos que interferem na configuração destes acordos e as transações aos quais sustentam. Sob o campo teórico da ECT, a frequência, a incerteza e a especificidade dos ativos são consideradas atributos das transações, e, portanto, influenciadoras dos sistemas de governança (WILLIAMSON, 2000).

A frequência relaciona-se com a regularidade com que as relações ocorrem entre os agentes. Espera-se que quanto maior seja a frequência destas relações, menores serão os custos de transação (GULATI; NOHRIA; ZAHERR, 2000). Isso porque a frequência tem a capacidade de diminuir custos fixos médios relacionados à obtenção de informações, que interferem na elaboração de contratos complexos, e na criação de reputação, que representa um meio para diluir o comportamento oportunista (FARINA, 1999; JARILLO, 1988).

A incerteza reflete o receio de que não haja informação suficiente para que o acordo seja celebrado entre as partes (FARINA, 1999). Isso leva os agentes a não terem condições de prever acontecimentos futuros e estimar as perdas derivadas do comportamento oportunista (MACHER; RICHMAN, 2008). A ausência de informações impede a convicção de que os contratos sejam perpetuados, gerando custos de transação superiores (WILLIAMSON, 1973).

A especificidade do ativo relaciona-se à impossibilidade de alocação de um determinado ativo em outras transações sem gerar custos (WILLIAMSON, 2000). Quanto maior a especificidade do ativo, maior a perda de valor ao transferi-lo de uma transação específica para outra (FARINA, 1999). Isso implica na relação de dependência dos agentes envolvidos, que pode representar uma situação de ganhos mútuos, quando existe confiança envolvida, ou um problema na iminência de incertezas (ZYLBERSZTAJN, 2005). As formas de especificidade dos ativos podem ser distintas, segundo Williamson (1985). Estas podem consistir em especificidade geográfica, física, de capital humano, de ativos dedicados, de qualidade superior e temporal. Diante destas características, a especificidade do ativo pode receber especial atenção, visto a capacidade de representação precisa e mensurável das relações (ZYLBERSZTAJN, 2005). Além disso, a 
especificidade dos ativos pode variar ao longo do tempo, movida, principalmente, pelas inovações tecnológicas (JARILLO, 1988).

Em vista das diversas possibilidades de combinações de comportamento dos agentes e das características das transações, as estruturas de governança podem assumir formatos baseados desde o mercado spot até a integração vertical (FARINA, 1999). Entre estes dois extremos existem formatos diferenciados de arranjos das transações, chamados de híbridos, que combinam diferentes níveis de riscos e de salvaguardas, cujo uso de contratos mostra-se presente e determinante (WILLIAMSON, 1985).

Não há, a priori, uma estrutura de governança superior às demais. $\mathrm{O}$ conceito de eficiência, útil a uma análise de competitividade, apoia-se na adequação da estrutura de governança às características da transação a qual se vincula (FARINA, 1999). Com isso, busca-se alcançar o equilíbrio entre as propriedades dos mercados e as de hierarquias com a coordenação entre empresas por intermédio de mecanismos organizacionais (GRANDORI; SODA, 1995). Inclusive, é possível encontrar o uso de mais de um formato de arranjo em um mesmo sistema industrial (ZYLBERSZTAJN, 2005).

A ECT defende que as relações de envolvimento geram ganhos associativos a grupos em que os custos de permanecer em uma estrutura puramente de mercados são imputáveis (WILLIAMSON, 1973). Isso gera aumento do valor da organização pela via contratual, independente desta ser formalizada ou não, o que permite minimizar custos associados ao funcionamento dos mercados e opera como incentivo para as partes envolvidas no contrato (ZYLBERSZTAJN, 2005).

Inclusive, as relações colaborativas vão além dos arranjos verticais e abrangem relações em diferentes instâncias, uma vez que também existem incentivos para a organização horizontal enquanto ampliadora de valor da organização (FARINA, 1999). Isso ocorre devido ao potencial das relações interorganizacionais em fornecer acesso a informações, recursos, mercados e tecnologias; em proporcionar vantagens de aprendizagem e economias de escala e escopo; e, permitir que as empresas alcancem objetivos estratégicos com a partilha de riscos, etapas de cadeia de valor terceirizada e funções organizacionais (GULATI; NOHRIA; ZAHEER, 2000).

Este contexto suscita o papel das redes, que são modos de coordenação entre unidades organizacionais especializadas que encontram o justo equilíbrio entre a diferenciação e a integração, considerado um problema na estruturação da organização (GRANDORI; SODA,
1995). Leva,assim, a um modo de organização que pode ser utilizado pelos gestores para colocar suas empresas em uma altiva posição competitiva (JARILLO, 1988).

A cooperação entre as organizações fundamenta relações com ganhos de valor mútuo e subsidia estratégias competitivas (GRANDORI, SODA, 1995; JARILLO, 1988). Diante disso, as organizações determinam arranjos que proporcionam maior eficiência e escolhas devem ser feitas quanto à forma de coordenação das transações de modo que os custos de implantação não superem os benefícios que a estrutura proporciona (WILLIAMSON, 1985). Além disso, ainda que as ações colaborativas demonstrem potencial para geração de valor aos envolvidos, a coordenação não surge espontaneamente, sendo dependente da iniciativa dos agentes econômicos (FARINA, 1999). Isso implica na análise comparativa de múltiplas possibilidades antes da implantação de um arranjo específico (WILLIAMSON, 2000).

Todas estas ponderações demonstram que a ECT presta suporte aos sistemas produtivos de forma importante, mas, generalista. Devido a sua abordagem, associada à Teoria da Organização Industrial, esta teoria apresenta-se proeminente no segmento da economia agrícola (ZYLBERSZTAJN, 2005). Esta perspectiva microeconômica na agricultura apresenta-se apropriada à discussão das estratégias, das estruturas internas das organizações e das relações interorganizacionais deste segmento (FARINA, 1999).

Os debates sobre o agronegócio e sua representatividade econômica emergiram a partir do estudo de Davis e Goldberg (1957). Estes definiram o termo "agribusiness" e lançaram uma série de questionamentos sobre a evolução do agronegócio, que saiu de um estado de autossuficiência para um de interdependência complexa com grandes segmentos da economia industrial. O conceito de produção integrada no agronegócio cresceu exponencialmente devido à possibilidade do acompanhamento da conformidade com os elevados padrões de qualidade e redução dos custos de transação (MAERTENS; SWINNEN, 2015).

A agricultura e o comércio de alimentos continuam sendo permeados por um intenso processo de mudança, com implicações como os níveis crescentes de coordenação vertical, a consolidação da base de fornecimento e o aumento da dominação das grandes empresas multinacionais de alimentos (MAERTENS; SWINNEN, 2015). Devido às dinâmicas e constantes evoluções da agricultura, suas demandas merecem ser estudadas (DAVIS; GOLDBERG, 1957). 
A partir do estudo de Davis e Goldberg (1957), a literatura que surgiu é ancorada, principalmente, na Teoria da Organização Industrial (ZYLBERSZTAJN, 2005). Contudo, considerando que os sistemas agroindustriais são formados por segmentos que exibem diferentes graus de dependência mútua, os atributos das transações são relevantes na configuração da governança, enfatizando a contribuição da ECT (FARINA, 1999).

Sob a abordagem de sistemas agroindustriais, diversas pesquisas têm sido desenvolvidas ao longo dos anos (ZYLBERSZTAJN, 2005). Contudo, ainda existem nichos específicos que merecem a atenção dos pesquisadores. Segundo Macher e Richman (2008) dentre os estudos sobre agronegócio, poucas pesquisas se dedicam às análises estatísticas sistemáticas de operações deste segmento sob a perspectiva dos custos de transação. Zylbersztajn (2005) também indica a necessidade de avanços de estudos sobre o agronegócio a partir da perspectiva da ECT. Para isso, sugere que sejam investigadas as relações reais da produção, a quantificação dos elementos presentes nos contratos e as possíveis relações com as externalidades geradas, a expansão de pesquisas que utilizem testes quantitativos, a comparação dos resultados empíricos entre distintas teorias que tratam a firma como um nexo de contratos, a demonstração da coordenação como resposta aos desafios presentes nos sistemas agroindustriais, a expansão do conhecimento sobre as regras institucionais e suas influências e o estudo de formas híbridas, principalmente por meio de testes empíricos. Dentre as possibilidades de investigação citadas, emergem oportunidades de reforçar o uso da ECT para compreender o papel da coordenação de sistemas produtivos do agronegócio, assim como para investigar o sistema agroindustrial da mandioca.

\section{PROCEDIMENTOS METODOLÓGICOS}

Os dados da presente pesquisa foram obtidos em estudos sobre o sistema agroindustrial da mandioca. Realizou-se pesquisa bibliográfica seguindo os seguintes procedimentos: escolha das bases de dados, identificação dos termos da busca e definição da abrangência da busca. Foram utilizadas as bases de dados Scopus, Jstor, Scielo, Science Direct, Portal de Periódicos Capes, Banco de Teses da Capes e Google Scholar, respectivamente.

A transação típica avaliada é a venda da mandioca in natura para a indústria, que geralmente é uma farinheira ou fecularia. Com o objetivo de encontrar pesquisas que atendem à presente investigação, utilizaram-se nas buscas os termos-chaves "mandioca" e "fécula". A escolha destes termos visou encontrar pesquisas relativas ao sistema de produção de mandioca considerando sua comercialização para fecularias e farinheiras. Durante a busca, cada um dos termos-chaves foi combinado individualmente com cada uma das seguintes palavras: "cadeia", "rede", "sistema", "contrato"; "transação", "governança"; "coordenação", "competitividade"; "incerteza"; "garantia", "estratégia”, "agronegócio"; "agricultura familiar", "agroalimentar", "agroindustrial", "desenvolvimento", "relações sociais"; "integração vertical", "mercado", "arranjo" e "comércio". Além da busca combinada dos termos-chaves e das expressões em língua portuguesa, o procedimento foi reaplicado utilizando as mesmas palavras com as respectivas traduções para a língua inglesa. As buscas foram realizadas considerando o título dos estudos, o resumo e as palavras-chaves no período de 02 a 06 de dezembro de 2016 e não foram utilizados delimitadores temporais para a data de publicação dos estudos que compõe a amostra da pesquisa.

Selecionaram-se exclusivamente as pesquisas que tratam sobre a mandioca brasileira e sua relação com as indústrias ou que investigam as relações entre atores deste sistema produtivo. Portanto, desconsideraram-se as pesquisas sobre aspectos nutricionais, agronômicos ou biológicos ou que investigaram a mandioca de mesa ou cultivo de subsistência. O Quadro 1 indica a quantidade de estudos encontrados em cada uma das bases de dados pesquisadas.

QUADRO 1 - Quantidade de estudos sobre o sistema agroindustrial da mandioca por base de dados

\begin{tabular}{|c|c|}
\hline Base de dados & $\begin{array}{c}\text { Quantidade de estudos } \\
\text { encontrados }\end{array}$ \\
\hline Scopus & 3 \\
\hline Jstor & 0 \\
\hline Scielo & 4 \\
\hline Science Direct & 1 \\
\hline Portal Periódicos Capes & 5 \\
\hline Banco de Teses da Capes & 12 \\
\hline Google Scholar & 61 \\
\hline Sub Amostra & 86 \\
\hline Estudos repetidos & 28 \\
\hline Amostra final & 58 \\
\hline
\end{tabular}

Fonte: Dados da pesquisa 
Foi realizada uma conferência a fim de eliminar possíveis repetições de resultados. Com isso, identificou-se que 26 estudos apareceram em mais de uma base, sendo excluídos, perfazendo a amostra de 61 papers. Também foram realizadas verificações devido à possibilidade de que as pesquisas apresentadas em eventos e os estudos de pós-graduação poderiam estar publicados também em periódicos. Isso implicou na exclusão de 2 artigos apresentados em congressos e uma monografia de pósgraduação lato sensu, constituindo a amostra final de 58 pesquisas. Estas configuram 30 artigos de periódicos; 14 pesquisas divulgadas em congressos, seminários e afins; 13 dissertações; e, 1 tese.

A continuidade da pesquisa bibliográfica ocorreu com o uso da técnica de análise de conteúdo na captura, organização e análise dos dados. Segundo Bardin (1977), a análise de conteúdo é um conjunto de técnicas de análise das comunicações que utiliza procedimentos sistemáticos e objetivos de descrição do conteúdo das mensagens. Para isso, é necessário que haja organização da análise; codificação de resultados; categorizações; inferências; e, por fim, a análise das comunicações.

A categorização dos dados extraídos dos artigos é fechada e foi efetuada por meio de planilha do software Microsoft Excel, dispondo-os em linhas individuais. As colunas da planilha representam, em um primeiro plano, categorias de dados acerca das características das pesquisas da amostra, como o ano de publicação, título, autores, Revista/Programa de Pós-Graduação, método de abordagem da pesquisa, técnicas de pesquisa e teoria de base. Em um segundo plano, a categorização contemplou marcos conceituais da economia das transações, do ambiente institucional e das estruturas de governança. A técnica da categorização empregada foi a análise temática e o critério de categorização aplicado é o método lógicosemântico, cujo alcance da análise de conteúdo segue parâmetros e definições lógicas. A partir da categorização proposta foi possível codificar os resultados e realizar as inferências. O procedimento de análise dos resultados foi baseado na metodologia do Programa de Estudos de Agronegócio (PENSA) que associa as teorias da ECT e da Organização Industrial (ZYLBERSZTAJN, 2005). Considerando as técnicas metodológicas apresentadas, o estudo se desenvolve sob uma abordagem descritiva e qualitativa.

\section{ANÁLISE DOS RESULTADOS E DISCUSSÃO}

Nesta seção é apresentada a análise das pesquisas sobre o sistema agroindustrial da mandioca. Inicialmente, são relatadas as características metodológicas e os formatos de pesquisa. Posteriormente, são descritas as transações, o ambiente institucional e as estruturas de governança, permitindo compilar falhas de coordenação deste sistema já identificadas.

\subsection{Caracterização das Pesquisas sobre o Sistema Agroindustrial da Mandioca}

A amostra é composta por 58 pesquisas publicadas entre os anos 2000 a 2016. A Figura 1 demonstra a quantidade de pesquisas publicadas por ano.

$\mathrm{O}$ ano de 2007 contém maior número de pesquisas, totalizando 7, seguido do ano de 2015 com 6 publicações, dos anos de 2010 e 2011 com 5 publicações e dos anos 2005, 2006, 2009, 2012, 2013 e 2014 com 4 publicações cada. Do ano 2000 a 2005 existe uma média

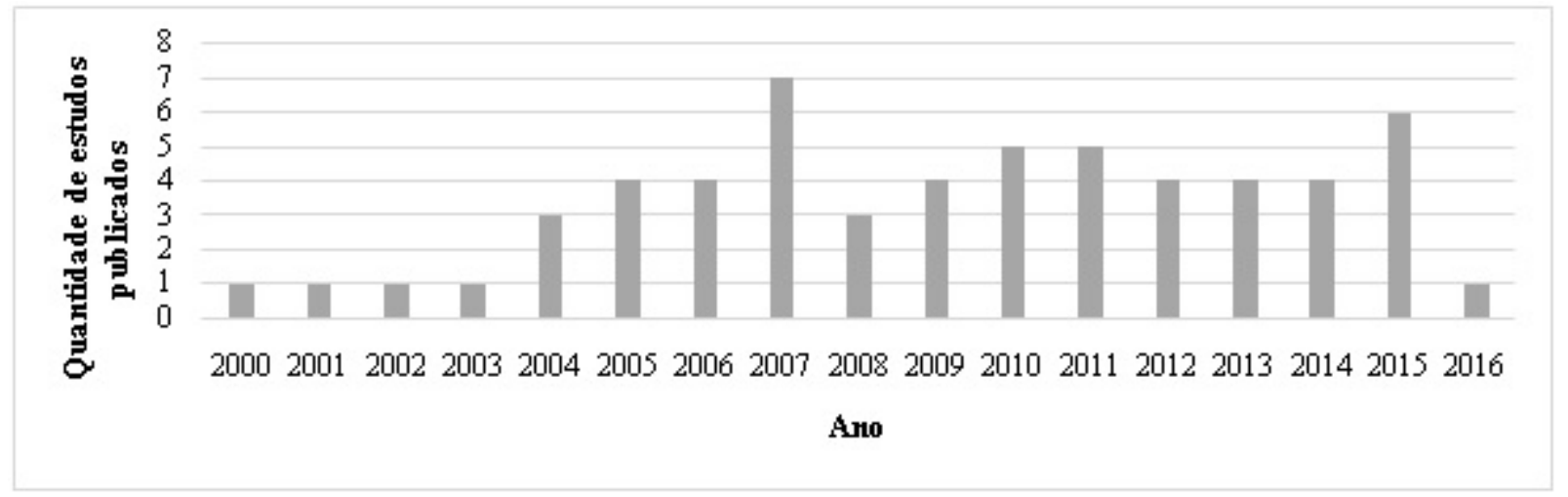

FIGURA 1 - Quantidade de estudos publicados por ano Fonte: Dados da pesquisa

Organizações Rurais \& Agroindustriais, Lavras, v. 20, n. 3/4, p. 257-275, 2018 
de 1,83 pesquisas por ano, de 2006 a 2010 o índice aumenta para 4,6 e a média anual de 2011 a 2016 é de 4. No entanto, o ano de 2016 tem apenas 1 publicação, diferente das médias de 2010 a 2015 que foi, em média, de 4,67 artigos por ano.

O decréscimo da quantidade de pesquisas sobre a cadeia da mandioca pode estar relacionado com a crise do setor e a ausência de melhorias na coordenação da cadeia, visto que a área plantada diminuiu $10 \%$ ao longo dos últimos anos analisados nesta pesquisa (DEPARTAMENTO DE ECONOMIA RURAL, 2015). No entanto, esta situação mostra-se favorável ao desenvolvimento de novas pesquisas, inclusive sobre a investigação das causas da rejeição em adotar práticas diferenciadas de coordenação expostas como essenciais pelos estudos anteriores.

As pesquisas da amostra centram-se primordialmente em estudos empíricos com metodologia de estudos de caso ou multi casos. Os métodos de coleta de dados ocorrem principalmente por meio de entrevistas (41\%), questionários (21\%) e ambos os métodos (5\%). As demais pesquisas utilizaram a pesquisa documental (33\%).Com isso, identifica-se que, apesar dos avanços gerados pelas pesquisas prévias, é possível ampliar o conhecimento científico sobre a cadeia da mandioca ao utilizar novas técnicas de coleta de dados, como a pesquisa etnográfica no estudo das relações sociais, a pesquisa-ação na implantação da coordenação horizontal e a pesquisa participante na percepção das indústrias na capacidade de coordenar verticalmente a cadeia.

Quanto ao método de abordagem, 86\% das pesquisas são estritamente qualitativas. As demais pesquisas (14\%) apresentam alguma forma de quantificação dos dados e respectiva análise estatística. Estes resultados são coerentes com a necessidade de ampliar as pesquisas quantitativas identificadas por Macher e Richman (2008) e Zylbersztajn (2005).

Outra análise realizada refere-se aos pesquisadores que atuam nesta temática. Foram identificadas ao todo 102 pessoas no conjunto das pesquisas. Contudo, 84 destes pesquisadores fizeram apenas um estudo sobre algum elemento da cadeia, demonstrando, que, em geral, o estudo da mandioca não apresenta prosseguimento pelo mesmo grupo de pesquisadores, o que inibe o aprofundamento do conhecimento científico.

Os autores mais expoentes foram Fábio Isaias Felipe (7 pesquisas), pesquisador do Centro de Estudos Avançados em Economia Aplicada da Escola Superior de Agricultura Luiz de Queiroz da Universidade de São
Paulo(CEPEA-ESALQ/USP), com estudos da cadeia agroindustrial da mandioca e derivados; Carlos Estevão Leite Cardoso (6 pesquisas), pesquisador da Empresa Brasileira de Pesquisa Agropecuária (EMBRAPA) da mandioca e fruticultura e pesquisador convidado do CEPEAESALQ/USP; Olivier François Vilpoux (5 pesquisas), professor pesquisador da Universidade Católica Dom Bosco (UCDB) com diversos projetos de pesquisas relacionados a mandioca; e, Giuliana Aparecida SantiniPigatto (4 pesquisas),professora e pesquisadora do Centro de Pesquisa em Administração e Agronegócios (CEPEAGRO) da UNESP. Estes pesquisadores estudam a mandioca sob amplas perspectivas, inexistindo estudos específicos das cadeias e redes, a competitividade ou a governança do segmento. Assim, a coordenação do sistema agroindustrial da mandioca representa uma agenda de estudo que ainda não foi utilizada em profundidade.

Foi identificado pouco rigor metodológico e uso de teoria de base em apenas 24\% (14) das pesquisas. Em 11 estudos a ECT foi utilizada como base teórica, em 1 pesquisa houve o uso da Teoria dos Contratos, em 1 pesquisa foi utilizada concomitantemente a ECT e a Teoria dos Contratos e em 1 pesquisa utilizou-se a abordagem da Nova Economia Institucional. Os demais estudos não utilizaram bases teóricas, sugerindo fragilidade nas análises apresentadas, e, consequentemente, justificando a veiculação das pesquisas em periódicos de menor impacto.

Quanto às publicações realizadas por meio de periódicos, identificou-se que a Revista Raízes e Amidos Tropicais, vinculada à UNESP, destacou-se com 6 artigos. Os demais periódicos mostram-se pulverizados. Dentre estas revistas, poucas estão indexadas em bases de dados internacionais, e, em geral, possuem baixa classificação pela Coordenação de Aperfeiçoamento de Pessoal de Nível Superior (CAPES). Este contexto, assim como as análises apresentadas anteriormente, principalmente quanto aos métodos empregados na análise dos dados e a recorrente ausência de bases teóricas indicam motivos pelos quais as pesquisas sobre o sistema agroindustrial da mandioca não têm demonstrado aprofundamento científico e poucas contribuições têm sido realizadas. Isso ocorre, principalmente, devido à preocupação na descrição das características das cadeias e das suas transações e na explicação da problemática que as envolve, sem, contudo, atuar de forma mais efetiva nas possibilidades reais de minimização das falhas de governança.

Dentre os eventos, o Congresso da Sociedade Brasileira de Economia, Administração e Sociologia Rural, 
realizado anualmente, abarca 10 estudos sobre o tema. Quanto as pesquisas relacionadas a pós-graduação strictu sensu, não há predominância de algum programa específico. É possível notar ainda que poucos estudos apresentados em eventos (1) ou de pós-graduação (2) foram publicados em revistas científicas. Mais uma vez, a descontinuidade da pesquisa sobre a sistema agroindustrial da mandioca é elencada e também justifica o pouco aprofundamento teórico-científico sobre suas falhas de coordenação.

\subsection{Configuração do sistema agroindustrial da mandioca elencada pelos estudos}

A análise dos resultados das pesquisas sobre a cadeia produtiva da mandioca permite um delineamento da configuração deste sistema. Para isso, é utilizada a estrutura de análise dos sistemas agroindustriais por meio da conjunção dos marcos conceituais da economia das transações, do ambiente institucional e das estruturas de governança.

O Quadro 2 demonstra a síntese dos resultados das pesquisas que compõem a amostra do atual estudo, ou seja, indica quais pesquisas trataram sobre cada um dos elementos do sistema agroindustrial da mandioca. Os elementos são analisados individualmente, em tópicos específicos.

\subsubsection{Caracterização dos Agentes e Pressupostos Comportamentais}

A Teoria da ECT possui como pressupostos a racionalidade limitada e o oportunismo e cada um destes aspectos representam as posturas comportamentais dos agentes. A racionalidade limitada foi amplamente percebida nas relações entre agentes do sistema agroindustrial da mandioca. Pigatto et al. (2015) indicam que os produtores de mandioca são afetados principalmente pelo desconhecimento sobre os fatores que interferem na formação do preço futuro da mandioca no mercado, mas, que a presença de coordenação da cadeia dilui problemas relacionados à racionalidade limitada.

Para Ferreira et al. (2009), nas indústrias de processamento a racionalidade limitada é posta como pouco importante, mas, relevante para os produtores, principalmente devido à falta de informações. Isso porque, normalmente, as indústrias possuem mais informações e não as repassam aos produtores, gerando relações conflitantes entre os elos da cadeia (ARAÚJO, ARRUDA JUNIOR, 2013; FELIPE, PAULILLO, 2014).

QUADRO 2 - Síntese dos resultados das pesquisas sobre o sistema agroindustrial da mandioca

\begin{tabular}{|c|c|c|c|}
\hline \multicolumn{3}{|c|}{$\begin{array}{l}\text { Elementos do sistema } \\
\text { agroindustrial }\end{array}$} & Estudos \\
\hline \multirow{4}{*}{ 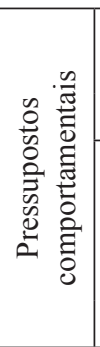 } & \multirow{2}{*}{$\begin{array}{l}\text { Existe } \\
\text { racionalidade } \\
\text { limitada? }\end{array}$} & Sim & $\begin{array}{l}\text { ALVES et al. (2007b); ARAÚJO, ARRUDA JUNIOR (2013); FELIPE (2015); FELIPE et al. } \\
\text { (2010); FELIPE, PAULILLO (2014); FERREIRA et al. (2009) }\end{array}$ \\
\hline & & Não & PIGATTO et al. (2015) \\
\hline & \multirow[t]{2}{*}{$\begin{array}{l}\text { Existe } \\
\text { oportunismo? }\end{array}$} & Sim & $\begin{array}{c}\text { ARIEIRA, FUSCO, SACOMANO (2012); BONCHRISTIANI (2007); CARDOSO (2003); } \\
\text { CHAVES, KUSTNER (2011); COIMBRA (2014); DOMINGOS, PEREIRA (2011); FELIPE } \\
\text { (2015); FELIPE et al. (2010); FELIPE, PAULILLO (2014); FERREIRA et al. (2009); } \\
\text { GOEBEL (2005); PINTO et al. (2006) }\end{array}$ \\
\hline & & Não & ANDRADE (2012); ARAÚJO, ARRUDA JUNIOR (2013); PIGATTO et al. (2015) \\
\hline \multirow{3}{*}{ 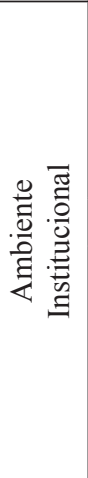 } & \multicolumn{2}{|c|}{ Atua contribuindo } & $\begin{array}{l}\text { ANDRADE (2012); ARIEIRA, FUSCO, SACOMANO (2012); BOURLEGAT, VALLE } \\
\text { (2005); CHAVES, KUSTNER (2011); DOMINGOS, PEREIRA (2011); FUINI (2011); } \\
\text { GOEBEL (2005); GRANJA JUNIOR, SILVA, BOURSCHEIDT (2010); LOPES, OLIVEIRA } \\
\text { (2009); RIBEIRO (2016); OLIVEIRA, GOMES, CONCEIÇÃO (2009); PIGATTO, } \\
\text { QUEIROZ, LOURENZANI (2015); VALLE (2006) }\end{array}$ \\
\hline & \multicolumn{2}{|c|}{ Atua prejudicando } & BEZERRA (2014) \\
\hline & \multicolumn{2}{|c|}{ Não atuante } & $\begin{array}{l}\text { ALVES (2012); ALVES et al. (2007a); ALVES et al. (2007b); ARAÚJO, ARRUDA JUNIOR } \\
\text { (2013); BATISTA et al. (2009); BONCHRISTIANI (2007); CAMARGO FILHO, ALVES } \\
\text { (2004); CARDOSO (2004); FELIPE, ALVES, CAMARGO (2010); FELIPE et al. (2010); } \\
\text { FREITAS, FARIAS, VILPOUX (2011); OLIVEIRA, SILVA, JUSTO (2013); OLIVEIRA } \\
\text { JUNIOR (2015); PIMENTEL, VITAL (2008); PINTO et al. (2006); PINTON (2002); } \\
\text { SANTINI, OLIVEIRA, PIGATTO (2010); VILPOUX (2008); VILPOUX (2011) }\end{array}$ \\
\hline
\end{tabular}

Continua... 
QUADRO 2 - Continuação...

\begin{tabular}{|c|c|c|c|}
\hline \multicolumn{3}{|c|}{$\begin{array}{l}\text { Elementos do sistema } \\
\text { agroindustrial }\end{array}$} & Estudos \\
\hline \multirow{6}{*}{ 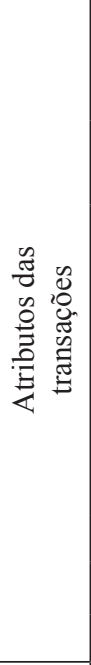 } & \multirow{2}{*}{$\begin{array}{l}\text { Existe } \\
\text { especificidade } \\
\text { de ativos? }\end{array}$} & Sim & $\begin{array}{l}\text { CARDOSO (2003); DOMINGOS, PEREIRA (2011); FELIPE et al. (2010); FELIPE, } \\
\text { PAULILLO (2014); FERREIRA et al. (2009); OLIVEIRA JUNIOR (2015); PIGATTO et al. } \\
\text { (2015); RANGEL et al.(2007) }\end{array}$ \\
\hline & & Não & $\begin{array}{l}\text { ARIENTE et al. (2005); COIMBRA (2014); GOEBEL (2005); SOUZA et al. (2005); } \\
\text { VILPOUX (2008); VILPOUX (2011) }\end{array}$ \\
\hline & \multirow[t]{2}{*}{$\begin{array}{c}\text { Existe } \\
\text { incerteza? }\end{array}$} & Sim & $\begin{array}{l}\text { ALVES (2012); ALVES et al. (2007B); ANDREOTTI (2013); ARAÚJO, ARRUDA JUNIOR } \\
\text { (2013); ARIEIRA, FUSCO, SACOMANO (2012); ARIENTE et al. (2005); BAZZO, } \\
\text { GAMEIRO (2007); BONCHRISTIANI (2007); BOURLEGAT, VALLE (2005); CAMARGO } \\
\text { FILHO, ALVES (2004); CARDOSO (2003); CHAVES, KUSTNER (2011); COIMBRA } \\
\text { (2014); DOMINGOS, PEREIRA (2011); FELIPE (2015); FELIPE et al. (2010); FELIPE, } \\
\text { PAULILLO (2014); FERREIRA et al. (2009); GABRIEL FILHO, PIGATTO, LORENZANI } \\
\text { (2015); GOEBEL (2005); OLIVEIRA JUNIOR (2015); PINTO et al. (2006); SOUZA et al. } \\
\text { (2005); VILPOUX (2011) }\end{array}$ \\
\hline & & Não & ANDRADE (2012); PIGATTO et al. (2015) \\
\hline & \multirow{2}{*}{$\begin{array}{l}\text { As transações } \\
\text { são frequentes? }\end{array}$} & $\operatorname{Sim}$ & ANDRADE (2012); FELIPE (2015); FELIPE et al. (2010); PIGATT \\
\hline & & Não & GOEBEL (2005); OLIVEIRA JUNIOR (2015) \\
\hline \multirow{3}{*}{ 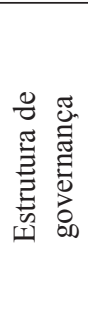 } & \multicolumn{2}{|c|}{ Mercado spot } & $\begin{array}{l}\text { FELIPE (2015); FELIPE et al. (2010); FELIPE, PAULILLO (2014); FELIPE, PAULILLO } \\
\text { (2015); FELIPE, RIZATO (2014); FERREIRA et al. (2009); FERREIRA (2004); SOUZA et } \\
\text { al. (2005); VILPOUX (2011); VILPOUX, SPROESSER, CAMPEÃO (2007) }\end{array}$ \\
\hline & \multicolumn{2}{|l|}{ Híbrido } & $\begin{array}{c}\text { ARIEIRA, FUSCO, SACOMANO (2012); BOURLEGAT, VALLE (2005); CARDOSO } \\
\text { (2003); CARDOSO, ALVES, FELIPE (2004); DOMINGOS, PEREIRA (2011); GOEBEL } \\
\text { (2005); PIGATTO et al. (2015); PINTO et al. (2006); SILVA, ASSUMPÇÃO, VEGRO (2000); } \\
\text { SILVA (2006); ROCHA JUNIOR et al. (2008) }\end{array}$ \\
\hline & Integração ve & ical & - \\
\hline \multirow[b]{2}{*}{ 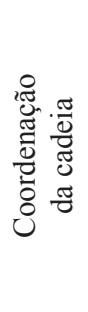 } & Sim & & $\begin{array}{l}\text { ARIEIRA, FUSCO, SACOMANO (2012); BONCHRISTIANI (2007); BOURLEGAT, } \\
\text { VALLE (2005); DOMINGOS, PEREIRA (2011); PIGATTO et al. (2015) }\end{array}$ \\
\hline & \multicolumn{2}{|l|}{ Não } & $\begin{array}{l}\text { ALVES (2012); ALVES et al. (2007B); ANDRADE (2012); ANDREOTTI (2013); ARAÚJO, } \\
\text { ARRUDA JUNIOR (2013); BEZERRA (2014); CARDOSO (2003); CARDOSO, BARROS } \\
\text { (2004); CARDOSO, FERREIRA FILHO E BATALHA (2001); FELIPE (2015); FELIPE, } \\
\text { ALVES, CAMARGO (2010); FELIPE et al. (2010); FERREIRA et al. (2009); OLIVEIRA } \\
\text { JUNIOR (2015); PINTO (2010); SOUZA et al. (2005); RIEDNER (2014); VELTHEM, KATZ } \\
\text { (2012); VILPOUX, SPROESSER, CAMPEÃO (2007) }\end{array}$ \\
\hline
\end{tabular}

Fonte: Dados da pesquisa

No entanto, a assimetria de informações está presente entre os segmentos da cadeia da mandioca, mas, não é uma condição esperada, visto que o fluxo de informações é relevante para o desenvolvimento da demanda dos produtos feitos a partir da mandioca e tem capacidade de beneficiar todos os agentes envolvidos e suas relações (BONCHRISTIANI, 2007; CARDOSO, 2003). A adaptação ligada à assimetria de informação indica a necessidade de buscar alternativas de melhor coordenação entre os agentes envolvidos nestas transações (DOMINGOS; PEREIRA, 2011).

O oportunismo também é tratado como um elemento presente nas transações da cadeia da mandioca (PIGATTO et al., 2015). Em uma das análises, o elo que mais se mostrou oportunista foi a indústria, principalmente pela negociação que realiza com os produtores que não têm condições de impor propostas de vendas com margens aceitáveis e adequadas diante da indústria (FERREIRA et al., 2009).

Outra percepção relatada é que alguns os produtores agem de modo oportunista. Isso porque foi identificado que numerosos agricultores descumprem os contratos de venda, priorizando quem lhes ofereça um preço melhor (SOUZA et al., 2005). Além disso, existem muitos produtores que plantam a mandioca somente quando há uma estimativa de preços bons, desestabilizando a oferta e demanda do 
produto (COIMBRA, 2014; RIEDNER, 2014). Existem também indícios de que o oportunismo é usual tanto pelos produtores rurais quanto pelas indústrias (CARDOSO, 2003; GOEBEL, 2005). No estudo de Domingos e Pereira (2011), a quebra de contrato por parte do produtor e do comprador foi analisada, demonstrando que o jogo de interesses se faz presente na cadeia da mandioca. Dentre os fatores que interferem no oportunismo, o uso do mercado spot é dado como um difusor destas práticas (FERREIRA, 2004). A frequência das transações também é citada como fator que é inversamente proporcional ao oportunismo (FELIPE, PAULILLO, 2014; PIGATTO et al., 2015).

Contudo, as situações oportunistas, por parte de agricultores e indústrias, devem ser repensadas a fim de promover e manter a competitividade (PINTO et al., 2006). Cadeias que se mostram mais integradas tendem a minimizar o oportunismo (ANDRADE, 2012; ARAÚJO, ARRUDA JUNIOR 2013; PIGATTO et al. 2015).

\subsubsection{Ambiente Institucional}

A redução dos custos de transação envolve mudanças institucionais (BONCHRISTIANI, 2007; GOEBEL, 2005; VILPOUX, 2011). Entre elas, são citadas a necessidade de políticas mais efetivas, o desenvolvimento de um ambiente que intensifique as relações horizontais e a possibilidade das indústrias assumirem a coordenação da cadeia.

Existe a necessidade de ampliar a atuação das instituições na emissão de políticas, principalmente públicas, que sustentem o desenvolvimento agrícola da mandioca em nível nacional e em regiões que têm características particulares (ANDRADE, 2012; BATISTA et al., 2009; BONCHRISTIANI, 2007; FELIPE, ALVES, CAMARGO, 2010; LOPES, OLIVEIRA, 2009; OLIVEIRA, GOMES, CONCEIÇÃO, 2009; OLIVEIRA JUNIOR, 2015; PIMENTEL, VITAL, 2008; PINTON, 2002; SANTINI, OLIVEIRA, PIGATTO, 2010).Dentre as políticas públicas, espera-se que os governos intervenham no equilíbrio econômico da cadeia produtiva da mandioca, assim como dos seus derivados (CAMARGO FILHO, ALVES, 2004;CARDOSO, 2003;SANTINI, OLIVEIRA, PIGATTO, 2010). Para isso, antes é preciso investigar os verdadeiros influenciadores do preço deste mercado, visto que Andreotti (2013) indica que as flutuações dos preços da raiz de mandioca não são compatíveis com os preços dos produtos industrializados, configurando a existência de assimetria de precificação.

Quanto ao ambiente institucional, destaca-se que a rede de relações multidimensionais e interescalares configura a dinâmica de aprendizagem coletiva, em um processo de spillover, do qual se beneficiam, principalmente, os produtores de mandioca (VALLE, 2006). Ações conjuntas dos agentes da cadeia produtiva poderiam conduzir a mandiocultura brasileira a elevados níveis de competitividade em mercados de concorrência crescente (FELIPE, ALVES, CAMARGO, 2010; GOEBEL, 2005; OLIVEIRA, SILVA, JUSTO, 2013; SILVA, 2006). Neste contexto, destacam-se as aglomerações de estabelecimentos, instituições e organizações na forma de arranjos produtivos locais (APL) (FUINI, 2011).

Bourlegat e Valle (2005) analisaram o APL mandioqueiro do Vale do Ivinhema, no estado de Mato Grosso do Sul, e identificaram que esse arranjo foi capaz de atrair o apoio de várias instituições públicas e privadas, tanto de natureza técnica quanto administrativa, e mostrou-se importante para o fortalecimento de organizações locais relacionadas aos atores.

A associação é outra forma de arranjo institucional e atua como organizadora do processo. Desempenha o papel de geração de trabalho e renda; melhoria da produção e comercialização da farinha da mandioca, alimentação e habitação; valorização da mandioca e de seus derivados; ampliação do conhecimento; fortalecimento da integração social e autoestima dos agricultores familiares; e, criação de reputação do produto relacionando-o à qualidade (ANDRADE, 2012; CHAVES, KUSTNER, 2011; DOMINGOS, PEREIRA, 2011; OLIVEIRA, GOMES, CONCEIÇÃO, 2009; PINTO et al., 2006; RIBEIRO, 2016).

Contudo, associações também têm apresentado falhas no sistema agroindustrial da mandioca. Associações de indústrias não têm apresentado um comportamento de coordenação da cadeia, visto que são cercadas de conflitos de interesses (BONCHRISTIANI, 2007). Também identificou-se que as cooperativas perdem sua função social quando possuem heranças culturais autoritárias, individualistas e paternalistas (CHAVES; KUSTNER, 2011). Também chama atenção a não formalização de contratos de entrega e de preços, deteriorando a credibilidade das associações (ARIEIRA; FUSCO; SACOMANO, 2012).

Outras entidades que se mostram relevantes no contexto institucional são as financeiras, as seguradoras, as agências de assistência técnica, os conselhos municipais e os sindicatos, (GOEBEL, 2005; OLIVEIRA, GOMES, CONCEIÇÃO, 2009; OLIVEIRA, SILVA, JUSTO, 2013). Surge, então, um espaço a ser priorizado pelas instituições envolvidas em processos de extensão rural de valorização dos diferentes sistemas produtivos encontrados no segmento da mandioca (PINTO et al., 
2006). Ou seja, há necessidade de adoção de sistemas cada vez mais ajustados aos atributos das transações (RANGEL et al., 2007). As indústrias também se mostram capacitadas para desenvolver meios de coordenação da cadeia (RIEDNER, 2014). Para isso, as indústrias têm colocado à disposição dos agricultores um mix de tecnologia (FELIPE et al., 2010).

Outra forma de rede social é formada pelos agricultores, pesquisadores e empresários que têm se organizado principalmente por meio de reuniões das Câmaras Setoriais, Conselhos Municipais de Desenvolvimento Rural e programas governamentais, ligados principalmente pelas inovações tecnológicas (LOPES; OLIVEIRA, 2009). No entanto, esta ainda não é uma prática disseminada no ambiente brasileiro.

\subsubsection{Transações}

As transações, sob o prisma da ECT, são influenciadas por atributos. Estes são representados pela especificidade dos ativos, a incerteza e a frequência que influenciam os custos de transação e a eficácia das empresas.

\subsubsection{Atributos das Transações}

A especificidade da mandioca tem abordagens divergentes. Em uma delas, a especificidade do ativo é considerada baixa, justificando a ausência de contratos mais completos (GOEBEL, 2005; SOUZA et al., 2005; VILPOUX, 2011). Em outras abordagens, a mandioca é considerada um produto com especificidades em suas formas de transação.

A especificidade física é defendida por Felipe e Paulillo (2014) e Pigatto et al. (2015). Isso porque a qualidade das raízes de mandioca, medida por meio da quantidade de amido, é fator essencial para a produtividade das indústrias. Ou seja, a diferenciação de produto pela qualidade surge como uma estratégia de acesso a novos mercados (RANGEL et al., 2007). Em vista disso, as indústrias pagam melhores preços aos produtores que entregam mandioca com maior teor de amido, elevando a preocupação dos agricultores quanto à qualidade do produto cultivado (DOMINGOS; PEREIRA, 2011).

A mandioca proveniente dos contratos tem melhor qualidade se comparada ao mercado spot, considerando que aqueles permitem o gerenciamento da produção, colheita e processamento (FELIPE, PAULILLO, 2015; ROCHA JUNIOR et al., 2008). Também é necessário que haja um maior volume de investimentos por parte das indústrias de transformação em equipamentos e tecnologia para buscar a melhor qualidade possível, tanto dos produtos industrializados quando do cultivo da mandioca (ARIEIRA; FUSCO; SACOMANO, 2012).

A especificidade locacional é defendida por Cardoso, Alves e Felipe (2007), Domingos e Pereira (2011), Felipe e Paulillo (2014) e Felipe e Paulillo (2015). Estes pesquisadores explicam que devido aos altos custos de transporte, suportados normalmente pelos produtores, a procura por indústrias mais próximas interfere na decisão de formalização da venda. A minimização dos custos provenientes da logística é fundamental, principalmente para os pequenos agricultores (DOMINGOS; PEREIRA, 2011).

Cardoso, Alves e Felipe (2007), Domingos e Pereira (2011), Felipe e Paulillo (2014), Felipe e Paulillo (2015) e Pigatto et al. (2015) também defendem que a mandioca apresenta especificidade temporal. Isto pela rápida perecibilidade do produto após a sua colheita. Entretanto, nos períodos de escassez de oferta, há considerável aumento nas distâncias para a aquisição de mandioca (FELIPE; PAULILLO, 2015).

As decisões de produção ocorrem anteriormente à comercialização e estão relacionadas com as características das transações (PIGATTO et al., 2015). Por isso, o produtor de mandioca convive com a instabilidade de preços, o que implica em maior risco de mercado (SILVA, ASSUMPÇÃO, VEGRO, 2000; VILPOUX, 2011). A incerteza ao produtor também pode ser relacionada à disponibilidade de informações, visto que existe o receio de que o comprador, que normalmente possui mais informações sobre o mercado, está utilizando-se da assimetria de informações para efetuar o contrato (GOEBEL, 2005; OLIVEIRA JUNIOR, 2015; SILVA, 2006; SOUZA et al., 2005).

Outro elemento nem sempre acessível aos pequenos produtores são as informações técnicas sobre a cultura da mandioca (ARAÚJO; ARRUDA JUNIOR, 2013). Assim, os produtores atribuem maior atenção à incerteza exógena do que à incerteza endógena da produção. Este problema demonstra a possibilidade de ser minimizado com a intensificação das relações entre os agentes da cadeia (PIGATTO et al., 2015; SILVA, 2006).

As dificuldades enfrentadas pela indústria com a falta de matéria-prima podem ser consideradas seu gargalo produtivo (ARIEIRA, FUSCO, SACOMANO, 2012; OLIVEIRA JUNIOR, 2015). Além disso, a incerteza da indústria pode ser proveniente da qualidade das raízes (ARIENTE, et al., 2005; FELIPE, PAULILLO, 2014; GOEBEL, 2005) e desvios de entrega, principalmente nos momentos de escassez de oferta (FELIPE; PAULILLO, 2015).

A previsão da demanda também foi considerada como um elemento que gera incerteza na cadeia da 
mandioca (VILPOUX, 2011). Em vista disso, Gabriel Filho, Pigatto e Lorenzani (2015) sugerem a utilização do sistema baseado na inteligência artificial fuzzy para realizar simulações que podem reduzir o grau de incerteza sobre a transação entre os agentes.

As características da transação na cadeia da mandioca demonstram que existe forte dependência entre os seus agentes (CARDOSO, 2003) e que as relações estabelecidas entre produtor/processador são de baixa confiança e compromisso (COIMBRA, 2014). Isso contribui com o entendimento de que o relacionamento de longo prazo e a confiança são importantes para a coordenação do sistema (FELIPE; PAULILLO, 2015).

As análises sobre a frequência das transações não são unânimes. Pesquisas empíricas demonstraram, em alguns casos, que a frequência não é observada no sistema agroindustrial da mandioca (GOEBEL, 2005; SOUZA, et al., 2005). Em outros estudos, a frequência faz parte das relações entre os agentes desta cadeia (FELIPE, 2015).

$\mathrm{O}$ aumento da frequência nas transações, em muitos casos, pode diminuir os custos de transação, independente da escolha do modo de governança (FELIPE, PAULILLO, 2015; FERREIRA, 2004; OLIVEIRA JUNIOR, 2015). Isso por que essas situações corroboram com a reputação entre as partes, minimizando o desenvolvimento do comportamento oportunista, e, consequentemente, diminuindo os custos de transação (FELIPE, 2015). Inclusive, isto estimula a ocorrência de contratos informais, sendo a proximidade geográfica um fator que reforça ainda mais esta forma de contrato (PIGATTO et al., 2015).

Também foi destacado que os produtores que têm a mandioca como principal fonte de renda apresentaram maior tempo de relacionamento com as mesmas indústrias (PIGATTO et al., 2015). Contudo, identificou-se também que relacionamentos de longa data entre produtores e empresas não são tão cooperativos e nem se sustentam em caso de perdas de um lado da relação (ARIEIRA, FUSCO, SACOMANO, 2012; VILPOUX, 2011). Ou seja, empiricamente, a frequência das transações pode tanto reforçar vínculos cooperativos a ponto de não haver necessidade de contratos formais, como permitir que ineficiências sejam descobertas e gerar práticas oportunistas.

\subsubsection{Estruturas de Governança}

A Organização Industrial preocupa-se com a formação de grupos estratégicos e estruturas de governança, inibindo gargalos para o desenvolvimento da cadeia produtiva. Complementando esta visão com os preceitos da ECT, as estruturas de governança variam desde a configuração pautada no mercado, passando por formatos híbridos e chegando até a hierarquia. Apesar das empresas escolherem modos de coordenação que minimizam os custos de transação, estes não são necessariamente os mais eficazes.

No sistema agroindustrial da mandioca prevalecem as transações por meio do mercado spot, sem qualquer controle sobre a produção (FELIPE, 2015; FELIPE, PAULILLO, 2014; FERREIRA, 2004; VILPOUX, 2011). Pelo mercado spot, as indústrias não têm controle sobre a qualidade da matéria-prima oferecida pelos produtores. Portanto, esta estrutura de governança apenas é viável para as indústrias nos períodos de oferta elevada de mandioca, quando muitos produtores passam a procurá-las para a comercialização do produto. Com isso, as indústrias podem escolher quais relacionamentos com determinados produtores desejam manter (FELIPE; PAULILLO, 2015). Inclusive, nestas situações, este formato de governança tem apresentado menores níveis de custos de transação (ARIENTE, 2006; VILPOUX, SPROESSER, CAMPEÃO, 2007).

Este cenário é avaliado sob duas formas distintas. Um deles é justificado pela confiança existente entre os agentes produtores e compradores, que pode ser resultado da interação social que surge da especificidade física e temporal (PIGATTO et al., 2015). A outra perspectiva indica ausência de confiança, tanto dos produtores quanto das indústrias, como motivo para o pouco uso de contratos na venda antecipada da produção de mandioca (GOEBEL, 2005; SOUZA et al., 2005; VILPOUX, 2011).

A demonstração de interesse, por parte dos produtores, pelos contratos se deve ao fato deste ser uma exigência para o financiamento da produção (FELIPE; PAULILLO, 2014) ou pelos plantios de larga extensão (DOMINGOS, PEREIRA, 2011; RIEDNER, 2014). No entanto, como a produção é normalmente influenciada por fatores não controláveis pela firma, esta não pode ser exclusivamente gerenciada por meio de contratos (FELIPE; RIZATO, 2014).

Quando utilizados, os contratos comumente possuem uma configuração de baixa complexidade (GOEBEL, 2005; FELIPE, 2015) e tendem a inserir cláusulas que viabilizam o desenvolvimento de todos os agentes da cadeia. Contudo, devido às características do mercado da raiz de mandioca, a sua formatação estabelece relações menos elaboradas (SOUZA et al., 2005). Além disso, de modo geral, a formalização de contratos entre os agentes é feita com o objetivo de suprir parte da necessidade da indústria, principalmente àquelas que atendem a mercados específicos ou têm contratos com compradores (FELIPE; PAULILLO, 2015). 
A formalização de contratos com garantias intermediárias ou garantias fortes (parcerias), como os arrendamentos, é identificada em alguns casos isolados, não configurando uma prática comum no sistema agroindustrial da mandioca (FELIPE, PAULILLO, 2015; VILPOUX, SPROESSER, CAMPEÃO,2007). O mesmo ocorre com a integração vertical, que se mostra pouco eficaz em indústrias de processamento, visto que a extensão das propriedades rurais necessária à produção das raízes de mandioca é muito grande para suprir a demanda industrial e a integração por parte dos produtores demanda elevados investimentos, comumente inacessíveis a esses agentes (FELIPE, PAULILLO, 2014; FELIPE, PAULILLO,2015).

Existem, ainda, indícios de que os arranjos variam de um ano para outro e de que há a adoção de mais de um arranjo ao mesmo tempo (VILPOUX,2011). A utilização de mais de uma forma de governança minimiza a vulnerabilidade das indústrias quanto ao abastecimento, considerando a especificidade temporal e locacional (FELIPE, 2015; FELIPE, PAULILLO, 2014). A presença simultânea de arranjos diferentes pode ser explicada pela indefinição do desempenho e custos de transação do setor (VILPOUX, 2011).

\subsection{Coordenação do Sistema Agroindustrial da Mandioca e Possibilidade de Avanços nos Estudos}

O Brasil possui vantagens competitivas no cultivo de mandioca em relação aos principais países exportadores, tais como área agricultável disponível e grande variedade de solos e climas (FELIPE, ALVES, CAMARGO, 2010; VILPOUX, 2008). A irregularidade no fornecimento de mandioca às indústrias de transformação e as oscilações dos preços são indicados como problemas potenciais (ALVES et al., 2007b; CARDOSO, BARROS, 2004; CARDOSO, ALVES, FELIPE, 2007; FELIPE, RIZATO, 2014; GOEBEL, 2005).

No entanto, a falta de coordenação da cadeia da mandioca é identificada por diferentes pesquisadores (ALVES, 2012; ALVES et al., 2007b; CARDOSO, ALVES, FELIPE, 2007; CARDOSO, BARROS, 2004; FELIPE et al., 2010; SOUZA et al.,2005; VILPOUX,2011) como elemento negativo na competitividade deste setor. Isso mostra que esta cadeia não está preparada para as oportunidades que surgem a partir das mudanças de hábitos de consumo, da substituição de importações, do desenvolvimento de novos produtos para a industrialização e das alterações nas políticas energéticas (CARDOSO, 2003; RANGEL et al., 2007).

Dentre os fatores que limitam a competitividade são citados o baixo nível de informação dos produtores sobre o mercado consumidor dos produtos industrializados (ALVES et al., 2007b; BAZZO, GAMEIRO, 2007; RIBEIRO, 2016), baixa profissionalização dos agentes (SOUZA et al., 2005), conflitos entre produtores e indústria, gestão inadequada da matéria-prima (ALVES, 2012; CARDOSO, ALVES, FELIPE, 2007; FELIPE, ALVES, CAMARGO, 2010; PINTO et al., 2006), vulnerabilidade dos produtores a condições climáticas e quebras de produção (OLIVEIRA; GOMES; CONCEIÇAO, 2009), baixa capacitação gerencial dos produtores e ausência de informações contábeis sobre o custo de produção (ARAÚJO, ARRUDA JUNIOR, 2013; DOMINGOS, PEREIRA, 2011; FERREIRA et al., 2009; RIEDNER, 2014; SILVA, 2006), resistência dos agricultores no uso de técnicas modernas de plantio e colheita (PINTO, 2010), inexistência de barreiras à entrada de novos agentes (SANTINI; OLIVEIRA; PIGATTO, 2010) e existência de barreiras à saída desta cadeia, em regiões onde prevalecem tal atividade (OLIVEIRA JUNIOR, 2015).

Deve-se considerar que os atributos das transações não são os únicos fatores determinantes das estruturas de governança. Histórico, cenário macroeconômico, custos de oportunidade e mercados também têm a sua importância, o que pode inclusive mudar o mix de governança (FELIPE; PAULILLO, 2015). Além disso, a dinâmica da cadeia mostra-se heterogênea em todo processo ao comparar regiões brasileiras distintas e em relação a indústrias de fécula e farinha (ALVES, 2012; COIMBRA, 2014; GRANJA JUNIOR, SILVA, BOURSCHEIDT, 2010).

O avanço substancial da contratualização é sugerido como oportuno para assegurar a renda agrícola aos produtores e o abastecimento industrial (ARAÚJO, ARRUDA JUNIOR, 2013; CARDOSO, ALVES, FELIPE 2007; FELIPE, et al., 2010; FELIPE, PAULILLO, 2015; GOEBEL, 2005; SILVA, ASSUMPÇÃO, VEGRO, 2000; SOUZA, et al., 2005). Para isso, é preciso que a oferta de garantias seja repensada, visto que dirigentes de indústrias não consideram esta possibilidade ideal (ALVES et al., 2007a). Existe, portanto, uma discrepância entre a percepção dos pesquisadores e dos agentes da cadeia quanto ao uso de contratos formais enquanto instrumentos de coordenação.

Cardoso, Ferreira Filho e Batalha (2001) indicam a necessidade do desenvolvimento de instrumentais alternativos em que se possam realizar predições quantitativas dos efeitos da adoção de políticas públicas e decisões gerencias internas às firmas. Cardoso e Barros (2004) e Coimbra (2014) sugerem a busca de melhorias na produtividade e nos preços pagos aos produtores rurais. Para isso, são necessários incentivos para aumentar o crédito 
aos produtores, a ampliação da mecanização da cultura da mandioca (CARDOSO, BARROS, 2004; OLIVEIRA, SILVA, JUSTO, 2013; PIMENTEL, VITAL, 2008; PINTO et al., 2006) e o desenvolvimento de variedade de plantas mais ricas em amido (ALVES et al., 2007a; ALVES et al., 2007b; BAZZO, GAMEIRO, 2007; CARDOSO, BARROS, 2004; OLIVEIRA, GOMES, CONCEIÇÃO, 2009; VILPOUX, 2008). A configuração das redes sociais representa outra forma de minimizar as falhas do sistema agroindustrial da mandioca (LOPES, OLIVEIRA, 2009; PIGATTO, QUEIROZ, LOURENZANI, 2015).

Ainda que a coordenação da cadeia da mandioca vise, principalmente, a eficiência econômica aos seus agentes, outros recursos devem ser observados na coordenação das suas relações (FUINI, 2011; OLIVEIRA, GOMES, CONCEIÇÃO, 2009). A cultura da mandioca envolve e relaciona diretrizes agronômicas, ecológicas, socioeconômicas, simbólicas e culturais. A sinergia entre todos estes elementos gera a demanda por um diálogo entre as políticas públicas e a antropologia que pode fortalecer as propostas de valorização deste produto agrícola (FREITAS, FARIAS, VILPOUX, 2011; LOPES, OLIVEIRA, 2009; VELTHEM, KATZ, 2012). Isso permite agregar valor à cultura da mandioca (ALVES et al. (b), 2007; ARAÚJO, ARRUDA JUNIOR, 2013).Além disso, novos hábitos desenvolvidos pelos consumidores indicam a necessidade de novas formas de controle da produção, como o uso da rastreabilidade e da certificação, assim como o atendimento de princípios de preservação ambiental, justiça social e boas práticas na agricultura, associados à garantia do retorno econômico das atividades (OLIVEIRA, GOMES, CONCEIÇÃO, 2009; RANGEL et al., 2007).

As limitadas políticas públicas são consideradas ineficientes e têm demonstrado influência no declínio da produção de mandioca (BEZERRA, 2014; OLIVEIRA, SILVA, JUSTO, 2013). Com isso, políticas privadas se mostram adequadas ao desenvolvimento da cadeia da mandioca, pois, envolvem a integração e a complementaridade de competências nas ações dentro da cadeia produtiva, buscando estabelecer sistemas de produção mais sustentáveis e que possibilitem o fortalecimento do mercado interno e adequação dos produtos às exigências do mercado externo (OLIVEIRA, GOMES, CONCEIÇÃO, 2009; RANGEL et al., 2007).

Todos estes problemas vivenciados pelo sistema agroindustrial da mandioca são perguntas sem respostas aos integrantes desta cadeia, e, portanto, são possibilidades de avanço nos estudos. A partir disso, novas perspectivas podem ser abertas à cadeia da mandioca para que esta se insira em um ambiente competitivo e possa obter vantagens neste meio (ALVES et al., 2007a; FELIPE, PAULILLO, 2014; FELIPE, RIZATO, 2014; VILPOUX, 2008).

\section{CONSIDERAÇÕES FINAIS}

Por meio desta pesquisa, foram compiladas análises acadêmicas sobre a cadeia da mandioca brasileira e apresentou-se como a estrutura de governança, as transações e o ambiente institucional dessa cadeia agroindustrial são caracterizados nos estudos. O objetivo foi compreender, a partir dos resultados já apresentados em literatura científica prévia, quais caminhos a pesquisa pode tomar para avançar na disseminação de conhecimento sobre formatos eficientes de governança no sistema agroindustrial da mandioca.

A caracterização dos agentes quanto à racionalidade limitada demonstra que existe esforço de adaptação, principalmente por parte dos produtores. O motivo citado para a ocorrência deste comportamento é a dificuldade destes em acessar informações necessárias ao planejamento da comercialização da produção. Contudo, podem existir outros elementos que levem à racionalidade limitada, considerando que não foi identificado nenhum estudo específico sobre este aspecto. Em vista disso, são propícias pesquisas sobre o comportamento dos agentes da cadeia, como forma de identificar os fatores que resultam na incompletude nos contratos.

O oportunismo, conforme indicado pelas pesquisas, está presente entre os diversos elos da cadeia da mandioca e contribui para as falhas de coordenação e perda de competitividade do setor. Considerando que é citado por um número expressivo de pesquisas, este comportamento também carece de estudo específico para avaliar os motivos que o originam, assim como desenvolver meios para criar relações mais justas entre os agentes.

$\mathrm{O}$ ambiente institucional mostrou-se elemento importante na configuração da cadeia da mandioca. No entanto, poucos estudos relataram a existência de ambientes organizados a partir da necessidade de governança da cadeia ou que atendem com efetividade este objetivo. Os arranjos institucionais destacam-se como uma ampla possibilidade de estudo, visto que existem variadas formas de instituições. Dentre os fatores que foram citados como importantes, mas não foram explorados a contento, está a influência das políticas e dos padrões alimentares. Isso indica a possibilidade de estudos que analisem a relação entre a competitividade do sistema da mandioca e as novas demandas de atributos dos alimentos. 
Quanto aos atributos das transações, foram elencadas análises sobre a especificidade dos ativos, a incerteza e a frequência das transações. A especificidade dos ativos chama a atenção principalmente pela possibilidade de diferenciação do produto, inclusive por meio do apelo à denominação de origem. A certificação também pode ser um caminho para abrir as portas para a exportação da fécula e dinamizar a competitividade deste segmento, indicando possibilidade de estudos sobre este tema.

A incerteza foi destacada como um atributo percebido tanto pelos produtores quando pelas indústrias quanto à inexistência de informações de oferta e demanda, qualidade, preço e honestidade dos demais agentes. A formalização de contratos é uma opção para a redução de incerteza e tem sido analisada por diversos estudos, que, em geral, destacam a dificuldade na ampliação do seu uso. Em vista disso, existe uma demanda por estudos que indiquem formas alternativas de minimização das incertezas na cadeia da mandioca.

A percepção empírica da frequência das transações no sistema agroindustrial da mandioca gerou uma dualidade de resultados. Parte deles coincide com os princípios da ECT, que determinam que quanto maior a frequência das transações, maior a cooperação, e, consequentemente, menores os custos de transação. Curiosamente, também se identificou que a frequência das operações não foi suficiente para inibir práticas oportunistas. Este cenário surge como uma oportunidade para investigar uma possível fragilidade deste atributo quanto a sua relação com os custos de transação ou ainda de identificar se este elemento possui um peso menor em relação aos atributos da especificidade dos ativos e da incerteza na cadeia agroindustrial da mandioca.

Quanto a caracterização das estruturas de governança, não foi encontrada uma unanimidade quanto aos formatos que ofereçam menores custos de transação associados à elevação da competitividade. A pluralidade nas formas de sistemas agroindustriais da mandioca e suas respectivas particularidades demandam opções específicas a cada organização. Este contexto abre espaço para discussões, principalmente teóricas, sobre a abrangência de cada modo de estruturação das operações das firmas da cadeia da mandioca.

Ainda que muitos fatores tenham sido citados como motivadores dos desequilíbrios do sistema agroindustrial da mandioca, e que todos mereçam ser contemplados por estudos futuros, o fluxo de informações entre os agentes ocupou lugar de destaque sendo relacionado aos preceitos comportamentais da racionalidade limitada e do oportunismo, assim como com os atributos das transações. O sistema de informação presente na cadeia da mandioca ainda não foi tema de estudo. Em vista disso, sugere-se que este aspecto seja investigado quanto às origens das falhas nos fluxos de informações e sua relação com a governança da cadeia, assim como o papel que pode ser exercido por organizações públicas (universidades, empresas de pesquisa e extensão e outras) na divulgação de informações técnicas e de mercado como previsões de safra e preços do mercado da mandioca.

Em geral, a análise das pesquisas permitiu identificar que os estudos sobre a governança do sistema agroindustrial da mandioca no Brasil ainda não se mostram consolidados e que a quantidade de pesquisas sobre a cadeia da mandioca tem diminuído ao longo do tempo. Superadas as fragilidades exploratórias, que podem estar associadas com a crise do setor e a ausência de melhorias na coordenação da cadeia, os estudos devem avançar quanto aos objetos de análise, no refinamento dos métodos de pesquisa e no uso de bases teóricas consistentes. A redução da área plantada nos últimos anos é um convite à ampliação das análises sobre as relações entre este cenário agrícola mandiocultor e as falhas de coordenação da cadeia já evidenciadas por pesquisas anteriores. O rigor científico deve ser observado a fim de aprofundar o conhecimento teórico-empírico, especialmente quanto as falhas de coordenação e os meios de dissipá-las.

O presente estudo permitiu verificar quais caminhos os estudos trilharam na busca pelo conhecimento e aprimoramento do sistema agroindustrial da mandioca e reforçou o uso da ECT para compreender o papel da coordenação de sistemas produtivos do agronegócio. Os insights apresentados configuram um estímulo à continuação das pesquisas como forma de disseminação de conhecimento sobre formatos eficientes de governança deste segmento. Inclusive, as diversas possibilidades de pesquisas sugeridas indicam a viabilidade de instauração de projetos de pesquisas que atuem especificamente no estudo da governança da cadeia da mandioca. Todas estas considerações pretendem criar reflexões sobre a coordenação do sistema agroindustrial da mandioca, promovendo a atividade de pesquisa como elemento relevante e efetivo na elevação da competitividade deste segmento.

Destaca-se como limitação do estudo a análise centrada, exclusivamente, em estudos que abordaram as relações díades entre produtores e indústrias devido à ausência de pesquisas que contemplam a cadeia agroindustrial da mandioca com mais amplitude entre os seus elos, especialmente à jusante. Esta limitação, inclusive, é um convite para que novos estudos avaliem as relações entre os agentes deste sistema agroindustrial, de forma a 
compreender como o mercado internacional dos produtos derivados da mandioca é afetado pela ausência de arranjos institucionais eficientes.

\section{REFERÊNCIAS}

ALVES, Admar Bezerra. Análise do desempenho de cadeias produtivas agroindustriais da mandioca: estudo de caso nas principais regiões de produção do Brasil. 2012. 160f. Dissertação (Mestrado em Agronegócio), Universidade Federal do Rio Grande do Sul, Porto Alegre. 2012.

ALVES, Alexandre Florindo; et al. Caracterização das empresas produtoras de fécula de mandioca na região de Paranavaí-PR. Revista Raízes e Amidos Tropicais, Botucatu, v. 3, p. 1-4, 2007a.

Fatores críticos de competitividade para a cadeia produtiva de fécula de mandioca na região de ParanavaíPR. Revista Raízes e Amidos Tropicais, Botucatu, v. 3, p. 1-4, 2007b.

ANDRADE, Herbert Cristhiano Pinheiro de. Organização de produtores rurais para a gestão da cadeia produtiva da mandioca no nordeste paraense: um estudo de caso na Associação de Desenvolvimento Comunitário e Rural Bom Jesus. 2012. 77f. Dissertação (Mestrado em Administração) - Escola Brasileira de Administração Pública e de Empresas, Fundação Getúlio Vargas, Rio de Janeiro. 2012.

ANDREOTTI, Aline de Queiroz Assis. O poder de mercado e a formação dos preços da fécula de mandioca: uma análise para as principais regiões produtoras brasileiras. 2013. 105f. Dissertação (Mestrado em Economia), Universidade Estadual de Maringá, Maringá. 2013.

ARAÚJO, Richard Medeiros de; ARRUDA JUNIOR, Sebastião. Cultura da mandioca: estudo de caso no agreste potiguar à luz dos relacionamentos inter atores.Holos, Natal, n. 29 , v. $6,2013$.

ARIEIRA, Jailson de Oliveira; FUSCO, José Paulo Alves; SACOMANO, José Benedito. Relacionamento e coordenação da cadeia produtiva da mandioca no noroeste do Paraná. Journal of Agronomic Sciences, Umuarama, v.1, n.1, p.120-134, 2012.

ARIENTE, Marina; et al. Competitividade na indústria da fécula de mandioca: estudo exploratório. Revista FAE, Curitiba, v. 8, n. 2, p.53-60, jul./dez., 2005.
. Estratégia competitivas no agronegócio: estudo exploratório nas fecularias do estado do Paraná. 2006. 107f. Dissertação (Mestrado Profissional em Administração) - Faculdade de Gestão e Negócios, Universidade Metodista de Piracicaba, Piracicaba. 2006.

BARDIN, L. Análise de conteúdo. 3. ed. Lisboa: Edições 70, 1977.

BATISTA, Lourdes Regina Lopes, et al. Levantamento do sistema de produção da mandioca no agreste alagoano. In Congresso Brasileiro de Mandioca, 13, 2009, Botucatu. Anais... Universidade Estadual Paulista, Botucatu.

BAZZO, Raquel Silveira; GAMEIRO, Augusto Hauber. Sistema de informações agroindustriais da mandioca brasileira. Revista Raízes e Amidos Tropicais, Botucatu, v. 3, p. 1-4, 2007.

BEZERRA, Francisco de Assis Pinto. Declínio da produção de mandioca: os impactos econômicos no município de Santa Izabel, estado do Pará. Agroecossistemas, Belém, v. 6, n. 1, p. 17-41, 2014.

BONCHRISTIANI, Caetano Carlos. Coordenação e ambiente organizacional do sistema agroindustrial da mandioca: uma análise relacional sob a ótica do neocorporativismo. 2007. 149f. Dissertação (Mestrado em Desenvolvimento Regional e Agronegócio), Universidade Estadual do Oeste do Paraná, Toledo. 2007.

BOURLEGAT, Cleonice Alexandre Le; VALLE, Paulo Cezar Santos. Potencialidades endógenas do Arranjo Produtivo Local da fécula de mandioca no Vale do Ivinhema, MS. In Congresso Brasileiro de Mandioca, 11, 2005, Campo Grande. Anais...Campo Grande.

CAMARGo FILHO, Waldemar Pires de; ALVES, Humberto Sebastião. Produção e mercado de mandioca: análise de preços ao produtor. Informações Econômicas, São Paulo, v.34, n.9, p. 47-52, set. 2004.

CARDOSO, Carlos Estevão Leite. Competitividade e Inovação tecnológica na cadeia agroindustrial de fécula de mandioca no Brasil. 2003. $188 \mathrm{f}$. Tese (Doutorado em Ciências) - Escola Superior de Agricultura Luiz de Queiroz, Universidade de São Paulo, São Paulo. 2003. 
CARDOSO, Carlos Estevão Leite; ALVES, Lucilio Rogério Aparecido; FELIPE, Fábio Isaias. Preço mínimo de raiz de mandioca estabelecido nos contratos entre produtores e fecularias. Revista Raízes e Amidos Tropicais, v. 3, 2007.

CARDOSO, Carlos Estevão Leite; BARROS, Geraldo Sant'Ana de Camargo. Competitividade no segmento agrícola da cadeia de fécula de mandioca. In Congresso da Sober, 42, 2004, Cuiabá. Anais... Cuiabá.

CARDOSO, Carlos Estevão Leite; FERREIRA FILHO, Joaquim Bento de Souza; BATALHA, Mário Otávio. Competitividade na cadeia agroindustrial de fécula de mandioca noBrasil: uma proposta de análise. In Congresso Internacional de Economia e Gestão de Negócios (Networks) Agroalimentares, 3, 2001,São Paulo. Anais... Universidade de São Paulo, São Paulo.

CHAVES, Gilvania Nunes; KUSTNER, Rocio Castro. Cooperativismo e desenvolvimento local: análise da cooperativa agrícola dos produtores de mandioca de São Felipe/BA. In Encontro Anual da ANPUR, 14, 2011, Rio de Janeiro. Anais... Rio de Janeiro.

COASE, Ronald. The nature of the firme. Economica, v. 4, n. 16, p. 386-405, nov. 1937.

COIMBRA, Tomás Sassetoi. Mandioca: a cultura, a sua análise econômica e a respectiva cadeia produtiva no Brasil. 2014. 110f. Dissertação (Mestrado em Agronomia Tropical e Desenvolvimento Sustentável) - Instituto Superior de Agronomia, Universidade de Lisboa, Lisboa. 2014.

DAVIS, John H.; GOLDBERG, Ray A. A concept of agribusiness. Boston: Harvard University, 1957.

DEPARTAMENTO DE ECONOMIA RURAL. Análise da conjuntura agropecuária - mandioca - Safra 2015/2016. Secretaria de Estado da Agricultura e do Abastecimento do Estado do Paraná, 2015.

DOMINGOS, Hélde Araújo Domingos; PEREIRA, Benedito Dias Pereira. Relação contratual dos pequenos produtores rurais da comunidade "Cedral" município de Rosário Oeste - MT: coordenação vertical e a informalidade dos contratos na produção de mandioca. Revista de Estudos Sociais, Cuiabá, n. 26, v. 13, p. 1-17, 2011.
FARINA, Elizabeth M.M.Q. competitividade e coordenação de sistemas agroindustriais:um ensaio conceitual. Gestão \& Produção, v.6, n.3, p. 147-161, dez. 1999.

FELIPE, Fábio Isaías. Determinantes das estruturas de governança das fecularias na compra de mandioca no estado do Paraná. 2015. 133f. Dissertação (Mestrado em Engenharia de Produção), Universidade Federal de São Carlos, São Carlos. 2015.

FELIPE, Fábio Isaías; ALVES, Lucílio Rogério Aparecido; CAMARGO, Samira GaiadCibim de. Panorama e perspectivas para a indústria de fécula de mandioca no Brasil. Revista Raízes e Amidos Tropicais, Botucatu, v. 6, p. 134-146, 2010.

FELIPE, Fábio Isaías, et al. Organização e Coordenação na Indústria de fécula de mandioca no Brasil sob a ótica da economia dos custos de transação. In Congresso da Sober, 48, 2010, Campo Grande. Anais...Campo Grande.

FELIPE, Fábio Isaías; PAULILLO, Luiz Fernando de Oriani e. Diversidade de mecanismos de governança para a compra de mandioca pelas fecularias do estado do Paraná entre 2004 e 2013. Informações Econômicas, São Paulo, v. 44, n. 6, p. 48-59, nov./dez., 2014.

. Estudo multicaso das formas plurais de coordenação das fecularias na compra de mandioca no estado do Paraná. In Congresso da Sober, 53, 2015, Maceió. Anais... Maceió.

FELIPE, Fábio Isaías; RIZATO, Matheus. Relação entre contratos e preços na cadeia de produção da fécula de mandioca no Brasil: uma análise empírica. In Congresso da Sober, 52, 2014, João Pessoa. Anais... João Pessoa.

FERREIRA, Degson, et al. Uma análise da cadeia produtiva da mandioca em Ipiranga de Goiás à luz da Economia dos Custos de Transação. In Congresso da Sober, 47, 2009, Porto Alegre. Anais...Porto Alegre.

FERREIRA, Nildete Maria da Costa. Cadeia produtiva da farinha de mandioca na perspectiva da análise de filière e supplychain management: um estudo de caso das relações entre a agroindústria e a distribuição. 2004. 83f. Dissertação (Mestrado em Ciências em Engenharia de Produção), Universidade Federal do Rio Grande do Norte, Natal. 2004. 
FREITAS, César Gomes de; FARIAS, Cleilton Sampaio de; VILPOUX, Olivier François. A produção camponesa de farinha de mandioca na amazônia sul ocidental. Boletim Goiano de Geografia, v. 31, n. 2, p. 29-42, Jul./Dez., 2011.

FUINI, Lucas Labigalini. As novas dimensões do rural: território e arranjos produtivos locais. Revista Geografares, Vitória, n. 9, p. 103-122, Jul./Dez., 2011.

GABRIEL FILHO, Luís R. A.; PIGATTO, Giuliana Aparecida Santini; LOURENZANI, Ana Elisa Bressan Smith. Fuzzy rule-based system for evaluation of uncertainty transaction in cassava chain. Engenharia Agrícola, Jaboticabal, v.35, n.2, p.350-367, mar./abr., 2015.

GOEBEL, Márcio Alberto. Organização e coordenação do sistema agroindustrial da mandioca na microrregião oeste do Paraná. 2005. 148f. Dissertação (Mestrado em Desenvolvimento Regional e Agronegócio), Universidade Estadual do Oeste do Paraná, Toledo. 2005.

GRANDORI, Anna; SODA, Giuseppe. Inter-firm Networks: Antecedents, Mechanisms and Forms. Organization Studies, v. 16, n. 2, p.183-214, mar., 1995.

GRANJA JUNIOR, Joseane; SILVA, Tallyta; BOURSCHEIDT, Jessica Regina. O estudo da competitividade da cadeia produtiva da mandioca no Tocantins: uma análise comparativa com a cadeia produtiva agroindustrial do Paraná. In CONNEPI, 5, 2010, Maceió. Anais... Maceió.

GULATI, Ranjay; NOHRIA, Nitin; ZAHEER, Akbar. Strategic Networks. Strategic Management Journal, v.21, n.3, Special Issue: Strategic Networks, p. 203-2015, mar., 2000.

JARILLO, J. Carlos. On strategic networks. Strategic Management Journal. v. 9, p. 31-41, 1988.

LOPES, Clarindo Aldo; OLIVEIRA, Lia Maria. Instituições, pesquisadores e agricultores: relações sociais e profissionais orientadas para a construção social do mercado da mandioca. Revista Brasileira de Agroecologia, Recife, v. 4, n. 2, p. 302-306, nov. 2009.

MACHER, Jeffrey T.; RICHMAN, Barak D. Transaction cost economics: an assessment of empirical research in the social sciences. Business and Politics, v. 10, n. 1, may, 2008.
MAERTENS, Miet; SWINNEN, Johan. Agricultural trade and development: a value chain perspective. WTO Working Paper ERSD- 2015-04. World Trade Organization. Economic Research and Statistics Division, apr.2015.

OLIVEIRA, Antonio Renato Moura; SILVA, Antonio Joandson; JUSTO, Wellington Ribeiro. Análise da cadeia produtiva da mandioca no município de Araripe - CE em 2012. In Congresso da SOBER Nordeste, 8, 2013, Parnaíba. Anais... Universidade Federal do Piauí, Parnaíba.

OLIVEIRA, Jacson Tavares de; GOMES, Izaltiene Rodrigues; CONCEIÇÃO, Tácio Luís de Andrade. A mandiocultura na microrregião de Vitória da Conquista análise e perspectivas. Revista Educação, Tecnologia e Cultura, Salvador, n. 6, p. 82-86, jan./dez., 2009.

OLIVEIRAJUNIOR, Osmar de Paula. Custos de transação e canais de distribuição na cadeia produtiva da mandioca: o caso da região do Vale do Araguaia-GO. 2015. 114f. Dissertação (Mestrado em Agronegócio) - Escola de Agronomia, Universidade Federal de Goiás, Goiânia. 2015.

PIGATTO, GiulianaAparecida Santini, et al. Comercialização de mandioca no estado de São Paulo-Brasil: sistemas de produção e custos de transação. Agroalimentaria, v. 21, n. 40, enero-junio, 2015.

PIGATTO, Giuliana Aparecida Santini; QUEIROZ, Timóteo Ramos; LOURENZANI, Ana ElisaBressan Smith. Redes sociais de produtores de mandioca em regiões do estado de São Paulo. Interações, Campo Grande, v. 16, n. 1, p. 75-86, jan./jun., 2015.

PIMENTEL, Alex Carlos da Silva; VITAL, Tales Wanderley. Visão de futuro de agricultores da teia produtiva popular da mandiocultura na zona da mata de Pernambuco. In Congresso da SOBER, 46, 2008, Rio Branco. Anais... Rio Branco.

PINTO, Florentino Carvalho. Aspectos da cadeia produtiva da mandioca em Feira de Santana no distrito de Maria Quitéria (povoados de Lagoa Grande e Olhos D’água das Moças). Sitientibus, Feira de Santana, n. 43, p. 157-173, jul./dez. 2010.

PINTO, Leonardo de Barros et al. Caracterização da Produção de Mandioca e formas de inserção no mercado da região alta paulista. In Congresso da SOBER, 44, 2006, Fortaleza. Anais... Fortaleza. 
PINTON, Florence. Manioc et biodiversité: explorationdesvoies d'un nouveau partenariat. Nature Sciences Sociétés, v. 10, n. 2, p.8-13, april/june, 2002.

RIBEIRO, Joselito de Macedo. Cooperativas como ferramentas de gestão das atividades produtivas da mandioca: estudo de casos em três cooperativas no Estado da Bahia. Revista Conbrad, Maringá, v.1, n.1, p. 97-112, 2016.

SILVA, José Roberto da; ASSUMPÇÃO, Roberto de; VEGRO, Celso Luis Rodrigues. A inserção da fécula de mandioca no mercado de amido. Informações Econômicas, São Paulo, v.30, n.7, p. 31-44, jul. 2000.

SILVA, Luis Carlos da. Integração vertical contratual no agronegócio: um estudo no complexo agroindustrial da mandioca em Deodápolis, MS. 2006. 120f. Dissertação (Mestrado em Engenharia de Produção) - Faculdade de Engenharia, Arquitetura e Urbanismo, Universidade Metodista de Piracicaba, Santa Bárbara d'Oeste. 2006.

SOUZA, Emerson Fingerde, et al. A cultura da mandioca na região oeste do Paraná:um estudo da coordenação da cadeia sob a ótica da teoria dos contratos. Organizações Rurais e Agroindustriais, Lavras, v. 7, n. 1, p. 11-22, 2005.

RANGEL, Marco Antônio Sedrez; et al. Implantação e desenvolvimento da produção integrada demandioca em cinco regiões produtoras do Brasil.Revista Raízes e Amidos Tropicais, Botucatu, v. 3, p. 1-4, 2007.

RIEDNER, Lilian Navrotzki. Avaliação da sustentabilidade da agricultura familiar no oeste do estado do Paraná, em propriedades produtoras de mandioca, considerando sua participação nas fecularias. 2014. 144f. Dissertação (Mestrado em Desenvolvimento Rural Sustentável), Universidade Estadual do Oeste do Paraná, Marechal Cândido Rondon. 2014.

ROCHA JUNIOR, Weimar Freire da; et al. Avaliação de contratos: uma abordagem utilizando a Análise Fatorial de Correspondência. Revista de Economia Sociologia Rural, Brasília, v.46, n.2 Brasília, p. 455-480, abr.jun., 2008.

SANTINI, Giuliana Aparecida; OLIVEIRA, Sandra Cristina de; PIGATTO,Gessuir. Análise da relação das variáveis preço e produção da mandioca tipo indústria no estado de
São Paulo, 1996 a 2008. Informações Econômicas, São Paulo, v.40, n.3, p. 41-52, mar., 2010.

VALLE, Paulo Cezar Santos. A dinâmica do conhecimento entre os produtores da agricultura familiar no arranjo produtivo local da mandioca no Vale do Ivinhema. 2006. 86f. Dissertação (Mestrado em Desenvolvimento Local), Universidade Católica Dom Bosco, Campo Grande. 2006.

VELTHEM, Lucia Hussak va; KATZ, Esther. A 'farinha especial': fabricação e percepção de um produto da agricultura familiar no vale do rio Juruá, Acre. Boletim do Museu Paraense Emílio Goeldi - Ciências Humanas, Belém, v. 7, n. 2, p. 435-456, maio-ago., 2012.

VILPOUX, Olivier François. Competitividade da mandioca no Brasil, como matéria-prima para amido. Informações Econômicas, São Paulo, v. 38, n.11, nov. 2008.

Desempenho dos arranjos institucionais e minimização dos custos de transação: transações entre produtores e fecularias de mandioca. Revista de Economia e Sociologia Rural, Piracicaba, SP, vol. 49, nº 02, p. 271294, abr.jun., 2011.

VILPOUX, Olivier François; SPROESSER, Renato Luiz; CAMPEÃO, Patrícia. Avaliação dos sistemas de coordenação entre produtores e fecularias de mandioca através da Economia dos Custos de Transação. In Congressoda SOBER, 45, 2007, Londrina. Anais... Londrina.

WILLIAMSON, Oliver E. Markets and hierarchies: some elementary considerations. The American Economic Review, v. 63, n. 2, p. 316-325, may, 1973.

The economic institutions of capitalism: firms, markets, relational contracting. New York: Free Press, 1985.

Why law, economics, and organization? UC Berkeley Public Law and Legal Theory Working Paper Series. Social Science Research Network Paper Collection, 2000.

ZYLBERSZTAJN, Decio. Papel dos contratos na coordenação agro-industrial: um olhar além dos mercados. Revista de Economia e Sociologia Rural, Brasília, v. 43, n. 3, p. 385-420, jul./set., 2005. 
